\title{
Parâmetros para uma análise empírica da relação entre idéias, elites e instituições
}

Adriano Codato*

\section{Introdução'}

\begin{abstract}
A crise profissional e ideológica que tomou conta do estado-maior Ida política paulista depois de 1930 pode ser medida pela coleção de posições divergentes que os dirigentes do estado assumiram diante do governo federal, pela quantidade de vezes que eles romperam e reataram com o Presidente da República e pela exuberância das justificativas que deram ao público doméstico para cada um desses rodopios. Uma maneira objetiva de decidir esse drama foi não dispensar os atores, mas trocar de teatro. Na década seguinte, já sob o Estado Novo, o futuro Ministro do Trabalho (e, posteriormente, também da Justiça) Marcondes Filho, Vice-Presidente do Departamento Administrativo do Estado de São Paulo, exaltou o que seria, de fato, um feito:
\end{abstract}

Muitos e admiráveis milagres, de ordem moral e material, o Sr. Getúlio Vargas terá realizado e ainda realizará no desempenho da missão histórica que a Providência lhe confiou $[s i c]$. Mas, a meu ver, nenhum será mais belo, mais profundo e de maior ressonância do

\footnotetext{
Adriano Codato é Professor de Ciência Política da Universidade Federal do Paraná (UFPR), Editor da Revista de Sociologia \& Política e Coordenador do Núcleo de Pesquisa em Sociologia Política Brasileira (NUSP). Endereço eletrônico: adriano@ufpr.br.

1 A oportunidade para discutir mais sistematicamente as questões aqui tratadas surgiu no colóquio "Variações sobre um tema: interpretações do Brasil e do Estado Novo", realizado em novembro de 2007, em Florianópolis, na Universidade Federal de Santa Catarina (UFSC). Este ensaio é um desenvolvimento da conferência que apresentei, intitulada "São Paulo sob o Estado Novo".
} 
que este, que nos fez recuperar o verdadeiro e glorioso sentido de nós mesmos e ver que ele está, ainda e sempre, no âmago do próprio destino excelso do Brasil (MARCONDES FILHO, 1941, p. 195).

Esse milagre era "a sincera, entusiástica e definitiva integração de São Paulo" à União nacional. "Entusiástica integração" é um oximoro, considerando-se todos os antecedentes históricos: a revolução contra a confederação oligárquica encimada pelo Partido Republicano Progressista (PRP) em 1930; a Revolução Constitucionalista, em 1932, contra o governo tenentista e seus desacertos; o golpe contra o candidato da União Democrática Brasileira (UDB) em 1937 etc. Até quando ela seria definitiva é uma questão a se verificar, ainda que, àquela altura, não houvesse tantas outras possibilidades assim. Um dos problemas históricos mais significativos no intervalo 1930-1945 corresponde ao grau de sinceridade dessa assimilação e sua direção política. Em suma: o regime incorporou politicamente os paulistas ou os paulistas incorporaram ideologicamente o regime?

O objetivo geral deste artigo é fornecer algumas sugestões teóricas e metodológicas para se pensar, em um registro diferente do habitual, a questão empírica do transformismo ideológico da elite política de São Paulo nos anos 1940 e também, em termos mais amplos, as relações entre idéias, elites e instituições políticas. Por "transformismo" quero designar aquilo que Antonio Gramsci definiu com precisão: não apenas a passagem de indivíduos, em geral parlamentares (transformismo "molecular"), ou de grupos inteiros de um campo político (ou ideológico) a outro, mas um fenômeno mais complexo: a assimilação, "decapitação" e destruição das elites de um grupo inimigo. Assim, o transformismo é a fabricação "de uma classe dirigente cada vez mais ampla, [...] com a absorção gradual, mas contínua, e obtida com métodos de variada eficácia, dos elementos ativos surgidos dos grupos aliados e mesmo dos adversários e que pareciam irreconciliavelmente inimigos" (GRAMSCI, 2002, p. 286; p. 63).

Na primeira seção, defino melhor o assunto específico que me interessa tratar - aquilo que Anthony Giddens chamou de a "integração moral" de uma classe política - e seus desdobramentos analíticos possíveis. Na segunda, determino dois parâmetros novos de interpretação daquele enigma político, um de tipo social, outro 
de tipo político. Na terceira, apresento uma hipótese de trabalho para lidar com o problema empírico paulista e discuto dois termoschave em meu modelo: "ideologia de Estado" e "fórmula política". Por último, organizo e resumo os critérios de análise historiográficos e sociográficos aqui propostos.

Mas por que São Paulo? O que ele pode efetivamente dizer não de si mesmo, mas do tema?

É provável que o caso de São Paulo, em razão das questões específicas que envolve, a força dos partidos oligárquicos, a influência nacional das lideranças políticas regionais, o conflito aberto com o governo federal, o monopólio da produção do café etc. É provável que o caso de São Paulo, em razão das questões específicas que envolve - a força dos partidos oligárquicos, a influência nacional das lideranças políticas regionais, o conflito aberto com o governo federal, o monopólio da produção do café etc. -,não seja representativo (em termos estatísticos) da lógica política de cada estado da federação no pós-1930. Mas, por outro lado, também não é uma amostra enviesada (uma "exceção") do que teria ocorrido no Brasil, durante o Estado Novo, com as elites políticas estaduais. Ainda assim, o interesse em estudá-lo - mesmo sabendo de antemão dos impedimentos para produzir testes de hipóteses válidos, inferências causais e generalizações confiáveis em pesquisas nas quais $n=1$ (cf. KING, KEOHANE \& VERBA, 1994, p. 209ss) - deriva do fato de esse ser um "caso-limite" (em que as ocorrências do problema são mais intensas) e não um "caso crucial” (isto é, um único caso observável e decisivo para a explicação do problema considerado), na definição de Harry Eckstein (1975, p. 79-137). Logo, São Paulo sob Vargas é um ponto de partida para uma melhor circunscrição do problema de pesquisas desse tipo (pesquisas históricas sobre elites políticas), bem como para a exemplificação das regras de delimitação/construção da questão aqui tratada (o transformismo da elite política paulista) e até mesmo para a enumeração dos problemas mais relevantes de temas como esse (as relações entre idéias, elites e instituições políticas). Seu estudo efetivo deve permitir gerar hipóteses explicativas testáveis em outros contextos históricos (RUESCHEMEYER, 2003). Certas ocorrências, como se pode intuir, são mais significativas para o todo sem que seja preciso estudar tudo. 


\section{A integração moral da elite}

Quando se recorda do destino das elites políticas estaduais depois de 1937, há um assunto incontornável, e as fabulações clássicas sobre as relações conflituosas entre Getúlio Vargas e a classe dirigente paulista começam por se esquecer da transfiguração progressiva e pragmática da "doutrina constitucionalista", o cavalo de batalha de 1932, em uma nova fórmula política e terminam por se surpreender diante da assunção da ideologia, da mitologia, do vocabulário e dos simbolismos autoritários por aqueles mesmos políticos que deveriam zelar para que São Paulo fosse "o principal centro de resistência da Civilização contra a barbárie, do Civilismo contra o caudilhismo militar, do Direito contra a força, da Lei contra o arbítrio e da Liberdade contra a tirania" (MARQUES \& OLIVEIRA, 1934, p. 328).

De fato, e para todos os efeitos, o liberalismo oligárquico (doutrina oficial da classe dominante na I República) foi incorporado à constelação do pensamento autoritário ao mesmo tempo em que a maior parte da classe política paulista aderiu à ditadura do Estado Novo. No entanto, mais que uma disposição conformista (ou meramente calculista), o desenvolvimento do enredo político brasileiro nos anos 1940 demonstrou que, se houve uma adesão ativa dos paulistas ao regime ditatorial, ela expressou-se em pelo menos dois níveis diferentes: em primeiro plano, pela participação empenhada na gerência burocrática do aparelho regional do estado: uma facção importante da elite foi reunida na Interventoria e outra foi internada no Departamento Administrativo do estado, dois endereços-chave (e praticamente os únicos disponíveis) na configuração institucional do regime; em segundo plano (e este foi um processo bem menos visível e, por isso mesmo, bem menos tematizado), a aprovação entusiasmada ao "varguismo" exprimiu-se pela mudança de sensibilidade da classe política paulista em relação à natureza, aos propósitos e ao conceito de "governo nacional". Essa última alteração significa, em resumo, que os políticos de carreira de São Paulo acabaram por acatar, sem questionar nem se questionar, a ideologia, a teoria e os valores autoritários (predominantes) do novo mundo político.

Todavia, pôr a questão da ideologia da classe dirigente não é apenas pôr a questão de uma vaga "legitimidade" do regime ou da 
indução de um comportamento mais leal ou, ainda, da assunção de uma atitude mais racional das facções subordinadas das oligarquias diante do poderoso comando federal. É indagar, na realidade, sobre a "integração moral" da classe política e sobre a harmonia ideológica desse dileto grupo, combinação cuja profundidade depende essencialmente da comutação dos quadros de referências mentais das elites. No caso, "integração 'moral' designa o grau em que aqueles que ocupam posições de elite partilham idéias comuns e um ethos moral comum; e quão conscientes eles são de uma solidariedade total" (GIDDENS, 1974, p. 5).

O propósito específico deste ensaio é expor e explicar não propriamente o progresso histórico desse processo de integração moral (os fatos políticos e seu encadeamento ao longo de uma sequiência temporal fixa) - aspecto ligado ao problema historiográfico da "cooptação" dos paulistas -, mas as condições institucionais e sociais que tornaram possível a solidariedade ideológica interelite, uma das bases do sucesso e da duração do Estado Novo. Esse objeto empírico - a coesão da classe política - recobre uma questão mais "teórica" e que está no miolo do caso aqui considerado: o processo de formação, difusão e assimilação de crenças, portanto, o processo de reprodução social e sua mediação pelo político (as instituições políticas) e pelo ideológico (tanto os aparelhos e as práticas quanto as doutrinas e as crenças). Não pensá-lo equivale a assumir que a coerência desse universo é, em certa medida, anterior ou inata a ele. Embora esses três problemas estejam conjugados - a reprodução dessa formação social, a coerência política do regime e a unidade ideológica da elite -, é mais produtivo, ao abordá-los, apresentar separadamente: i) algumas proposições sobre as relações (estruturais e circunstanciais) que ocorrem no mundo político (nesse mundo político, bem entendido, já que não advogo um "modelo geral") e ii) os efeitos ideológicos sobre os agentes políticos e a formação de sua consciência e de sua conduta.

\section{Conformismo lógico e compromisso pragmático}

Os políticos de carreira de São Paulo não foram, evidentemente, os únicos a deixar-se levar pelo Estado Novo, tripular seus apare- 
lhos e jurar sua ideologia. Os intelectuais, ao menos um significativo número deles, também. Evelina Dagnino explicou os dois aspectos decisivos que concorreram para essa afinidade: i) o compromisso explícito que tanto os pensadores do regime quanto os operadores do Estado tinham com "o desenvolvimento e a promoção de uma cultura nacional como um componente fundamental do [processo] de construção da Nação" e ii) "a crença", compartilhada por ambos, "no Estado como o agente fundamental da transformação social" (DAGNINO, 1985, p. 430-431; sem grifos no original).

De acordo, mas a elite política e, mais exatamente, a elite política paulista deveria ter outros motivos e guiar-se por outras razões. Crentes na superioridade de suas tradições e descrentes da necessidade de qualquer transformação social radical, sobretudo por um Estado que não comandavam e por uma elite que não influenciavam, qual a melhor palavra para exprimir o fenômeno que os acometeu, de passar a falar e pensar em uma nova língua? "Adequação provisória" ao arranjo político em vigor (como uma estratégia para conservar-se à tona e manter suas posições)? "Adaptação evolutiva" (por mutação ou por mimetismo)? Ou "conversão definitiva" à ideologia do Estado autoritário segundo o modelo paradigmático das conversões religiosas?

O estudo desse "pensamento fraterno" (cf. VARGAS, 1940, p. 50), a compreensão de seu sucesso em unir e integrar a elite política em uma nova fórmula política ${ }^{2}$ e especialmente a análise do movimento da classe política paulista em direção a ele não precisam recorrer apenas, ou em primeiro lugar, a explicações intencionais,

2 Para uma definição mais precisa, ver a discussão adiante, proposta por Gaetano Mosca. Adianto que utilizo essa expressão conforme o sentido defendido pelo autor, o qual insistiu que a base jurídica objetiva e o preceito moral sobre os quais se apóiam o poder e a autoridade da classe política comportam certo grau de racionalização, sem, entretanto, fazer da fórmula política uma verdade científica nem, tampouco, convertê-la em uma lorota pura e simples. Em suas palavras, o "autoritarismo" - entendido aqui como um conjunto de idéias (portanto, uma ideologia) e um conjunto de atitudes socialmente partilhadas (isto é, um corpus de normas e valores) - é uma "força social que contribui decisivamente para consolidar uma organização política e dar coesão" à sociedade. Para que uma fórmula política seja realmente eficaz, ela deve basear-se ou nas crenças mais fortes de um grupo social ou nas crenças do grupo social mais forte, isto é, daquele que detém o predomínio político (MOSCA, 1939, p. 71). 
baseadas no cálculo racional dos agentes e em sua ação interessada, para, estrategicamente, garantir a todo custo seu poder e sua influência - como se o posicionamento dos políticos diante das idéias políticas dominantes fosse comandado tão só pelo desejo, consciente, de preservar suas posições dominantes. Por outro lado, também não é necessário recorrer a explicações irracionais (por assim dizer), baseadas na prevalência de uma ideologia dominante - a "ideologia autoritária" -, que abarca tudo e todos e que, no limite, absolve $o$ analista da tarefa de descrever e esclarecer os movimentos (inconscientes) de empatia, simpatia ou antipatia em relação a ela. Essa concepção sobre como funciona o campo ideológico só justifica e desculpa retrospectivamente seus atores autômatos. Portanto, nem estratégia consciente do sujeito nem determinação mecânica do sistema, como resumiu Pierre Bourdieu (2004, p. 130).

Todavia, não é possível ignorar que escolhas nesse terreno tendem também (mas não só) a ser comandadas pelo instinto de sobrevivência política do Homo politicus racional, para aproveitar a denominação de Weber. Boa parte do problema, entretanto, não é, como se sabe, a eleição das preferências políticas, mas a formação inconsciente das preferências ${ }^{3}$. Há, antes de tudo, um "conformismo lógico" (esticando e adaptando um pouco a idéia de Émile Durkheim) atado a maneiras convergentes de refletir e agir e que fundamenta, em cada espaço do mundo social, uma sensibilidade especial comum a todos os grupos, um esprit de corps entre os agentes sociais. Esse "corporativismo" (tradução disponível para o português da expressão francesa) é, dirá Bourdieu (1989, p. 111), "bem mais profundo que a simples solidariedade de interesses compartilhados", embora envolva, do mesmo modo, acrescento eu, interesses muito concretos, que podem ou não ser perseguidos taticamente. O "corporativismo" é tão mais forte na classe política, penso eu, quanto mais ameaçada de desintegração ela se vê ou se sente. As crises políticas tendem, por isso, a reforçar - antes de esgarçar - o corporativismo (e o conformismo) daqueles que têm algo a perder.

3 Entre os críticos mais sensatos do paradigma da escolha racional na política está Steven Lukes. Para uma defesa da abordagem sociológica (cf. LUKES, 1980, p. 17-18). 
De onde ele provém? Seria útil diferenciar aqui o esprit de corps, que decorre das posições objetivas ocupadas pelos agentes na estrutura social (processo ou efeito ligado a uma lógica classista e à gramática dos interesses de classe), do effet de corps, processo derivado das posições ocupadas no "mercado econômico" (em que o critério distintivo e definidor é a profissão, ou melhor, o pertencimento a um "corpo profissional”). O effet de corps, postula Bourdieu, pode ser derivado ainda do pertencimento a uma família, a uma parentela, a uma nacionalidade, a associações disso e daquilo etc.; ele é também prerrogativa de agrupamentos muito restritos, do tipo "clube". Essa definição encaixa-se, a propósito, no caso de uma classe política bastante reduzida, como, por exemplo, a do Estado $\mathrm{Novo}^{4}$.

$\mathrm{O}$ effet de corps, esse sentido de reciprocidade, de pertença a um mesmo repertório simbólico, produzido e garantido por uma identidade comum, é mais importante e mais influente que o esprit de corps. Quanto mais homogêneos socialmente forem os grupos considerados, prevê Bourdieu (1985, p. 73), mais seus "efeitos sobre os corpos" tendem a prevalecer e triunfar; quanto mais bem posicionados no espaço social estão esses grupos, como no caso da classe política paulista (portanto, quanto maior "a probabilidade de as profissões funcionarem como corporações”), mais esses efeitos propendem a aumentar.

Ao lado do "conformismo lógico" que modela, encaixa e solda a consciência prática e a própria prática dos agentes, há um "compromisso pragmático" entre os agentes políticos e a estrutura de poder que difere desse acordo tácito de consciências sobre as regras dos comportamentos sociais de seus agentes e das crenças que instituem os crentes, embora seja tão decisivo quanto o primeiro, já que constitui também ou tanto mais uma precondição de funcionamento do mundo político.

O "compromisso pragmático" (não encontrei uma expressão mais denotativa para a idéia) refere-se não aos interesses subjetivos dos

4 Conforme minhas estimativas (otimistas) e baseando-me na definição posicional de "elite", a elite estadual de São Paulo somaria algo em torno de 50 indivíduos, talvez menos. Sandra Amaral, adotando critérios muito semelhantes, encontrou 31 indivíduos na elite rio-grandense-do-sul (cf. AMARAL, 2006, p. 147). 
agentes (instituídos pelo sprit de corps e reforçados pelo effet de corps), mas aos interesses objetivos da estrutura política enquanto tal.

Os interesses da estrutura, ou melhor, os interesses sociais inscritos objetivamente na estrutura política, não são interesses, a priori, intangíveis, ou interesses permanentes, mas interesses na permanência. Eles antecedem os propósitos (as escolhas) e as prerrogativas (o poder) dos agentes e os interesses que devem "objetivamente" representar e se impõem. Essa realidade e essa verdade devem ser reconhecidas (é preciso comprometer-se com elas) e aceitas pragmaticamente antes mesmo de se entrar no jogo político, como condição, aliás, para se entrar no jogo. A sugestão de Raymundo Faoro para interpretar o emblema político do II Império - "não há nada tão parecido com um conservador quanto um liberal no poder" 5 - descreve bem melhor o axioma animista aqui presumido de um "poder" acima dos poderes sociais:

[A frase não diz] que o liberal transita para o campo conservador, sem rubores e sem dramas de consciência, e vice-versa, em alusão ao presumido incaracterístico dos partidos imperiais. O que se contém na frase célebre é coisa diversa: o liberal, por obra do poder e quando no poder, atua, comanda e dirige como um conservador, adjetivando no máximo sua filiação partidária. Não se trata do descompromisso maquiavélico e oportunista de uma elite solidária, que, para mandar, muda de camisa, contanto que mande e continue mandando. [...] $\mathrm{O}$ liberal, se convertido em governo, cede às estruturas e à ideologia que the permitem dirigir o leme, leme unicamente feito para aquele navio, que só com ele pode navegar. Ele crê num dogma, mas para freqüentar a igreja, deve praticar o culto contrário, sob pena de excomunhão eterna (FAORO, 1994, p. 128-129; sem grifos no original).

Quanto mais corporativa for a classe política, isto é, quanto mais preocupada estiver em promover seus interesses ("sua" ordem, "seu" poder, "suas" posições, "suas" idéias etc.), mais a estrutura política irá constranger suas ações, dando-lhe apenas o que ela pode pedir. O conformismo não está no princípio da ação "racional”, funcionando, no caso, como motivo; o conformismo lógico é o resultado

5 A frase do Visconde de Albuquerque é, literalmente, a seguinte: "Nada tão parecido com um Saquarema como um Luzia no poder". 
do compromisso pragmático com a estrutura política. Por essa razão, pode ser percebido, superficialmente, como interesse mútuo.

\section{Ideologia e fórmula política}

Como, precisamente, em um universo político tão heterogêneo, tão instável e tão propenso a conflitos como o universo estadonovista, aquela "fraternidade" recitada por Vargas foi produzida, acatada e garantida?

Minha hipótese é a seguinte: a presença, ainda que parcial, das elites estaduais nas estruturas políticas do Estado ditatorial - causa e efeito do compromisso pragmático com o sistema político e, por extensão, com o regime "varguista" - contribuiu decisivamente para acelerar o transformismo das oligarquias e, por essa via, para sua conversão intelectual à ideologia autoritária (o que é diferente, como se pode notar, de uma adesão genuinamente raciocinada). A existência de alguns mecanismos políticos na engenharia institucional do Estado Novo - e, entre eles, os departamentos administrativos dos estados 6 - encorajou sua nova identidade social e profissional (potencializando, portanto, o effet de corps) e, graças à transmissão e imposição de certos mandamentos e pensamentos do topo para a base do sistema estatal, viabilizou a "unidade psicológica" da elite estatal, para falar nos mesmos termos sugeridos por Wright Mills ${ }^{7}$

Essa suposição ressalta, assim, as relações de obrigação recíproca que fundamentaram a unidade entre uma facção de elite e outra e a utilidade das instituições burocráticas como instâncias de mediação tanto política como ideológica. Mas, repare, ela não

6 Os departamentos administrativos foram criados pelo Decreto-Lei n. $1.202 \mathrm{em}$ 8 de abril de 1939 e passaram a funcionar no segundo semestre desse ano. Foram projetados para ser, ao lado da Interventoria Federal, um dos dois órgãos da administração estadual, consertando o vazio burocrático que havia, ou se imaginava haver, na área orçamentária. Sua composição variava conforme o estado e possuíam de quatro a sete membros. Tal qual uma câmara revisora, teriam de examinar todos os projetos de decretos-leis baixados pelo Interventor e pelos prefeitos municipais, podendo, quando fosse o caso, vetá-los.

7 Wright Mills chama de "unidade psicológica" da elite a unidade baseada na partilha dos mesmos valores, dos mesmos princípios, da mesma visão de mundo (cf. WRIGHT MILLS, 1981, p. 30). 
explica a assimilação do autoritarismo (movimento, aliás, que está na origem de sua ubiquiidade e eficácia), problema bem mais complexo que o consentimento (consciente ou não) ou a submissão (espontânea ou voluntária) a ele. Para avaliar como, concretamente, o lema Pro Brasilia fiant eximia tomou, enfim, o lugar do orgulhoso Pro São Paulo fiant eximia, é preciso ter presentes e integrar, nesse mesmo "modelo" explicativo, variáveis de três tipos: estrutural (ou histórica), organizacional (ou profissional) e comportamental. Elas foram construídas por indução e a hierarquia entre elas não está ainda muito clara para mim. Parto do mais geral para o mais específico, aproximando-me aos poucos do problema, visto que não tenho uma explicação causal para ele.

\subsection{A ideologia de Estado}

O espaço entre o início da década de 1930 e o fim da década de 1940 é um período particularmente complicado, porque é um período de transição: econômica (mudança do modelo de acumulação), política (mudança do modelo de dominação) e, principalmente, ideológica (mudança do modelo de justificação).

A passagem da economia agroexportadora para a economia urbano-industrial - propósito e produto da estruturação do Estado central como aparelho autônomo e poder soberano - é contemporânea da ultrapassagem da ideologia liberal e oligárquica, dominante na I e II Repúblicas, pela ideologia estatista e autoritária e pela imposição desta última como a língua franca da classe política. Por isso, não basta constatar a divergência e contrastar as diferenças entre uma temporada e outra. É obrigatório formular uma explicação para a súbita vocação autoritária desses agentes sociais. Esse temperamento, note-se, é mais do que um alinhamento automático à ideologia de Estado, isto é, ao sistema de "crenças formais e conscientes" baseadas nos "princípios ou posições teóricas gerais" que predominam nesse universo político - ainda que este tenha seus parâmetros, conteúdos e limites revelados por essa ideologia. É, ao lado do fato político propriamente dito, um fato simbólico, que implica a incorporação de determinadas formas de inteligência do mundo social e integração a determinados modos de visão, divisão 
e hierarquização do mundo político, isto é, a uma fórmula política. Conforme a discriminação de Raymond Williams (1992, p. 25-26), esses são "pressupostos, posturas e compromissos inconscientes" tanto dos agentes entre si como entre os agentes e a estrutura política.

"Ideologia de Estado" não tem aqui a conotação usual que o termo acabou por assumir na Sociologia Política brasileira depois de posto em circulação pelo conhecido ensaio de Bolívar Lamounier: uma ideologia oposta à ideologia de mercado ("liberal"), sinônimo daquilo que, na língua dos economistas, é chamado de "estatismo" (cf. LAMOUNIER, 1991, p. 343-374). Por "ideologia de Estado" quero designar um sistema de idéias produzido pelo Estado (ou, mais precisamente, por seus "intelectuais", em sentido amplo), dirigido, em grande medida, aos agentes do Estado e ao mundo político em geral e que tem como núcleo a apologia do poder de Estado. O "autoritarismo" - e, ao mesmo tempo, sua linguagem e sua mensagem - é, aqui, o paroxismo desse culto pagão da (justamente) autoridade do Estado sobre "a sociedade". O "culto do Estado e da sua autoridade" (cf. VIANNA, 1930) é a fórmula imaginada para se atingir a grandeza nacional, o domínio sobre os interesses egoístas de indivíduos e grupos, a modernização do Brasil etc. Uma visão parecida a essa é aquela que define a "ideologia populista" por seu elemento essencial: ofetiche do Estado na forma do culto ao Estado protetor (cf. BOITO JR., 1991, p. 77). Ricardo Silva, que utiliza a expressão "ideologia do Estado autoritário", enfatiza outro aspecto do problema. Seu estudo das idéias políticas (de Alberto Torres a Roberto Campos) propõe-se a entender de que maneira essa "formação ideológica específica" concorre "para a legitimação da estrutura de dominação do Estado autoritário" (SILVA, 2004, p. 56; sem grifos no original) ${ }^{8}$. Prefiro ver, além disso (ou antes disso), de que modo ela contribui para a produção dos agentes políticos que são, de toda forma, os vetores desse processo de validação.

A "construção estatal dos espíritos", não se deve esquecer, é um dos elementos que estão na base e na origem da constituição do poder de Estado (historicamente e "teoricamente") diante dos poderes privados e é, ao mesmo tempo, seu corolário.

8 Para a crítica do modelo de Lamounier, ver: Moraes (1986). 
Essas estruturas cognitivas são formas historicamente constituídas [...] das quais se pode traçar a gênese social. Generalizando a hipótese de Durkheim, segundo a qual as "formas de classificação" que os "primitivos" aplicam ao mundo são produto da incorporação das estruturas dos grupos nas quais eles estão inseridos, podemos supor que, nas sociedades diferenciadas, o Estado pode impor e inculcar de modo universal, na escala de certo âmbito territorial, estruturas cognitivas e de avaliação idênticas, ou semelhantes, e que é desse fato que deriva um "conformismo lógico" e um "conformismo moral” (expressões de Durkheim), um acordo tácito, pré-reflexivo, imediato, sobre o sentido do mundo (BOURDIEU, 1996, p. 115).

O caso aqui é que o efeito ideológico da ideologia de Estado não só tem origem no "microcosmo burocrático", graças ao discurso performativo sobre o Estado estabelecido pelos agentes do Estado, que se expressa nas idéias gerais de interesse público, vontade geral, universalismo de procedimentos, impessoalidade da função, razão de Estado etc., e nas idéias exclusivas de interesse nacional, vontade presidencial, personalismo institucionalizado etc. A ideologia de Estado - e este parece ser o ponto essencial - volta-se sobre os próprios agentes do Estado, promovendo e justificando seu poder e instituindo uma identidade social, profissional e política característica. Essa nova personalidade das categorias sociais de Estado (assessores técnicos, dirigentes burocráticos, militares em funções políticas, especialistas de todos os tipos: em Direito, em Economia, contas públicas etc.) pode ser, então, inteiramente compartilhada pelos políticos da oligarquia admitidos nas estruturas do Estado autoritário, sujeitos, portanto, às mesmas idéias autoritárias (nacionalismo, estatismo, corporativismo etc.) e ao efeito ideológico dessas idéias que aprovam seu poder e explicam suas funções. A transmutação do pessoal político nos estadosem juristas do Estado é produto e prova dessa nova percepção de si e do ambiente político. Esse acontecimento é impelido e reforçado por um Estado também em transformação (state-building), que requisita para si um discurso legitimador de seu poder e de sua autoridade (a ladainha dos políticos e dos ideólogos dessa temporada é exatamente esta: a celebração da "capacidade estatal"). Então, o Estado retribui reconhecendo a legitimidade intelectual e política daqueles que devem legitimá-lo. O culto do Estado termina, assim, por servir a todo o mundo político. 


\subsection{A fórmula política}

Analisar uma formação ideológica complexa como essa, que envolve uma substituição da ideologia política dominante e, ao mesmo tempo, uma tradução da ideologia dominante em uma linguagem política acessível, implica, como recomenda Terry Eagleton (1997, p. 55), "examinar o complexo conjunto de ligações ou mediações entre seus níveis mais e menos articulados”, isto é, entre a ideologia de Estado e a fórmula política autoritária.

Seria imprudente cogitar que todo o esforço ideológico dos pensadores autoritários, vazado em um registro muito intelectualizado, pudesse impressionar e empolgar os políticos profissionais. $\mathrm{O}$ comentário judicioso de Edgard Carone a esse respeito parece-me bastante convincente: Ademar de Barros, Agamenon Magalhães et alii não se comoviam muito com idéias abstratas nem se persuadiam das vantagens da nova ordem graças a filosofias políticas. Nem um nem outro "falava[m] em fórmulas ou ideais fascistas ou democratas". 0 que faziam era "seguir a tradição [política] existente e preconizar medidas [...] coronelísticas" (cf. CARONE, 1976, p. 264). Mas, até que ponto só o compromisso pragmático com a estrutura política e seu modo de operação eram suficientes?

Para compreender a ideologia política dirigente da classe politicamente dirigente é preciso entender o processo de conversão de um sistema de idéias predominante, a "ideologia autoritária”, ou, na linguagem que adotei e que julgo mais descritiva, a ideologia da autoridade do Estado autoritário, em uma fórmula política (naquele sentido postulado por Gaetano Mosca).

Abraham Kaplan e Harold Lasswell (1998) propuseram, também com base em Mosca, uma explicação sucinta e operacional para "fórmula política". Segundo eles, a fórmula política é parte do "mito político", isto é, do sistema ideológico e das formas de dominação simbólica. "Enquanto a doutrina política é a 'filosofia' do Estado e do governo, a fórmula política incorpora o direito público básico da sociedade" e o exprime como um padrão de práticas políticas específicas. "A doutrina constitui os postulados [...] da fórmula [política]; donde a sua exposição frequiente nos preâmbulos das constituições, sendo essas últimas uma expressão [também] 
importante da fórmula política" (idem). A fórmula política, por sua vez, elabora, em termos mais ou menos concretos, o conteúdo da doutrina política dominante. "Por exemplo, a doutrina política do direito divino dos reis pode, conforme a fórmula política, tomar a forma de um sistema de prerrogativas reais, regras de sucessão do trono, padrões de poder passíveis de serem exercidos por uma nobreza subordinada etc." (idem). Kaplan e Lasswell listam, ainda, mais algumas propriedades importantes da fórmula política como abordada aqui. Ela é, ao mesmo tempo, descritiva e prescritiva: por um lado, impõe a obediência a seus conteúdos e fornece a simbologia para justificar e enfeitar as práticas dos poderosos; por outro, e como extensão do primeiro movimento, garante que ela própria (a fórmula política vigente) seja "amplamente aceita como uma descrição correta de padrões e práticas de poder”, isto é, como uma descrição da realidade, como uma representação fiel do mundo político. Em segundo lugar, é preciso notar que, como a fórmula política é parte da dinâmica política efetiva, isso exige um processo de "interpretação contínua" (atualizações, adaptações, seleções, como propôs Raymond Williams para que ela continue sendo "aplicável". Por último, um regime político concreto "tende a ser complementado por práticas informais que [se] não são abertamente contrárias à fórmula política”, não resultam em "mudanças básicas na fórmula política", em grandes revoluções político-teóricas. Um expediente comum, nesse caso, são as várias interpretações jurídicas, os entendimentos legais, as convenções políticas sobre o que está realmente escrito na Constituição (KAPLAN \& LASSWELL, 1998, p. 163; p. 165; p. 169).

Neste espaço, não é possível realizar uma análise detalhada do campo intelectual nacional, que compreende um sem-número de correntes e partidos teóricos (cf. COSTA, 1967), mas é possível indicar ao menos, na topografia desse campo ideológico, alguns acidentes geográficos da década de 1940. Entre eles, destaca-se o discurso, muito sistemático (desde que reconstruído) dos sócios menores do ideário político do Estado Novo a respeito da "organização nacional" e suas formulações menos conceituais sobre a dimensão institucional do programa varguista, o que implica prolixas teorizações sobre o federalismo e a unidade nacional, o caráter inevitável 
dos processos de concentração e centralização do poder, o Estado "forte" e o personalismo governamental. Um lugar estratégico para ler essas idéias de segunda mão e estudar a reciclagem dos princípios gerais da ideologia de Estado e a difusão do dialeto autoritário é o periódico oficial do regime, Cultura Política ${ }^{9}$. Segundo Almir de Andrade, a revista representava um esforço consciente e planejado para a "recuperação intelectual da ideologia do governo", devendo ser "um trabalho mais sério", guiado "por uma preocupação mais teórica e analítica que propagandística" (Andrade apud DAGNINO, 1985, p. 343; sem grifos no original).

A soma aritmética das contribuições individuais dos escritores de Cultura Política não forma uma ideologia: são idéias que se alimentam de e alimentam um universo mental cujas balizas estão definidas pelos grandes pensadores do "regime forte". Seu editor tem razão em mencionar que, em sua revista, apesar do prestígio da publicação, "escreviam intelectuais de todas as carreiras, de todas as camadas" (ANDRADE, 1985, p. 9); só faltou dizer que a hierarquia no domínio dos produtores de explicações oficiais era muito estrita e implicava uma divisão minuciosa do trabalho em que os oficiais do Estado-Maior do autoritarismo nativo - os founding fathers da Ciência Política brasileira (Francisco Campos, Oliveira Vianna e Azevedo Amaral $)^{10}$ - estavam incumbidos da formulação de conceitos teóricos, interpretações históricas e racionalizações doutrinárias das instituições políticas que produzissem e garantissem a autoridade e a capacidade do Estado. Posteriormente, essa "sociologia" e suas descobertas seriam sistematizadas e traduzidas para uma linguagem mais objetiva, ou por eles mesmos, ou por alguns outros poucos intelectuais mais importantes (como o próprio Almir de Andrade, Monte Arrais, Oto Prazeres). Por último, essas idéias serão repetidas, explicadas e adaptadas a qualquer contexto possível e utilizadas

9 Cultura Política: Revista Mensal de Estudos Brasileiros foi publicada pelo Departamento de Imprensa e Propaganda (DIP) durante a maior parte de seu período de existência, de março de 1941 a outubro de 1945. Era o principal órgão teórico de difusão da ideologia estado-novista. Pretendia organizar a "cultura" de acordo "com a orientação geral do Estado e com o próprio ritmo da vida política" (ANDRADE, 1942, p. 9; sem grifos no original).

10 Para o título, ver: Lamounier (1982, p. 409ss.). 
em nome de qualquer argumento que servisse à causa por um time de ideólogos menores. O baixo clero dessa categoria social ocupa-se, então, de sua transcrição para uma linguagem bem menos pretensiosa e abstrata, apresentada com frequiência em um tom militante e combativo, o que dá à fórmula política do regime um aspecto muito mais "ideológico", por assim dizer, e menos "teórico", tornando-a pronta para o consumo. As idéias gerais daqueles primeiros sobre a formação histórica da nacionalidade, a doutrina constitucional implícita nas Cartas de 1824, 1891, 1934 e 1937 ou mesmo a descoberta da vocação natural do país transformam-se, nas centenas de artigos da revista, em defesa, a posteriori, do perfil do regime, do poder do Presidente e das políticas do governo. Todavia, as duas operações conjugadas (emissão e decodificação) são decisivas para produzir o que Thompson chamou de um "idioma intelectual" comum (cf. THOMPSON, 1998, p. 63; grifos no original), que será falado por outros, ou por todos, podendo inclusive servir de base para avançar e aperfeiçoar os fundamentos da ideologia teórica e (o que interessa aqui) combinar o vocabulário e o ideário da nova elite estatal ${ }^{11}$.

Ao que tudo indica, o glossário anexado à obra dos maiorais em Cultura Política pretende bem mais forjar uma identidade ideológica no interior do aparelho do Estado do que produzir um consentimento meditado da "sociedade civil" à cultura política autoritária (a revista olhando mais para dentro do que para fora). Se há uma mobilização importante de muitos nomes da literatura e das artes em geral para falar de "cultura" (como ilustração) e se esses intelectuais estão tanto na "sociedade civil" quanto nos departamentos do Estado, os assuntos políticos serão especialidade de uma elite intelectual postiça, que se confunde com a elite político-burocrática ou deriva diretamente dela (cf. CODATO \&

11 No número de novembro de 1941, o periódico Cultura Política trouxe uma seção nova, "Bibliografia sobre o Estado Novo". Era uma lista "de tudo o que se tem escrito sobre o Estado Novo, desde novembro de 1937, em livros, jornais, revistas etc., das capitais e do interior de todo o Brasil”. Esse inventário (são 106 escritores) dá uma boa medida do processo de fabricação de uma ideologia jurídico-política sob o disfarce, em geral, de hermenêutica constitucional. Confira: Bibliografia sobre o Estado Novo (1941). 
GUANDALINI JUNIOR, 2003, p. 145-164). Funcionários do regime convertidos em pensadores políticos tanto quanto pensadores empregados como funcionários do Estado: não é de estranhar-se a dependência ideológica desses amanuenses em relação ao governo nem a ausência quase completa de alteridade desse discurso em relação à realidade que pretende comentar.

O pensamento prêt-à-porter desses investigadores da organização política do regime ditatorial e sua percepção heterônoma e encantada da nova ordem giram basicamente sobre dois eixos: o das características institucionais e do valor decorrente daí, já que é, antes de tudo, um discurso normativo da antiga e da nova "realidade nacional"; e o das categorias conceituais criadas, com base nessa percepção, para ilustrar e comprovar a superioridade da nova forma de Estado/regime. Esse pensamento destoa da matriz, nesse aspecto mais circunspecta e menos redundante, porque aquela não abusa, tanto quanto ele, dos malabarismos verbais, das corrupções de sentido, das interpretações arbitrárias a que submete, sem piedade, a linguagem política tradicional: "federalismo centralizador" no lugar de Estado unitário; "governo forte" em vez de ditadura; "democracia social", "democracia funcional", "democracia sui generis" em vez de democracia política e assim por diante - essas serão, de resto, as palavras do idioma praticado pelos operadores do Departamento Administrativo paulista ${ }^{12}$.

\section{N.3. Profissionalismo e predisposição autoritária}

A influência recíproca entre esses dois processos (aquele que inventa outra identidade para esses indivíduos e uma nova razão de ser para seu poder, e este referido agora, que traduz uma ideologia da apologia do poder de Estado em um idioma político operacional), a influência sobre a personalidade autoritária dos agentes sociais é amplificada pelo efeito que a profissionalização política impõe, ou melhor, por aquele tipo de profissionalização exigido e produzido pelas regras do regime ditatorial.

12 Para ver o documento, cf. Codato (1997). 
A profissionalização é uma forma de especialização, à medida que compreende a assimilação dos padrões e dos valores básicos prevalecentes em uma dada atividade (BLACK, 1970, p. 865). Segundo conjectura Fred Block (1987, p. 201), "os state managers tendem a encaixar suas maneiras de pensar à sua nova situação ocupacional, assim como um executivo de empresa privada alteraria sua visão de acordo com um tipo de firma ou outra". Não se trata, no entanto, de mera manobra adaptativa, já que a investidura na função (e, daí, a prática do ofício, o desempenho no cargo e a assimilação do papel) tende a produzir uma identificação com o projeto autoritário. Isso pode ser verificado, por exemplo, na modulação dos discursos dos conselheiros do Departamento Administrativo de São Paulo.

Certamente, terceiro argumento, a introjeção dos valores do regime foi facilitada, em boa medida, aliás, por uma predisposição antidemocrática da elite. A classe política paulista, inclusive e principalmente sua facção dita liberal, tinha, antes de sua metamorfose completa, uma zelosa afinidade eletiva com uma das variantes do autoritarismo oficial, e a sensibilidade política da vanguarda paulista (tanto a getulista como a antigetulista) pode ser estimada baseandose na formulação de dois de seus celebrados representantes: Júlio de Mesquita Filho e Vicente Rao.

Nem é preciso ir além das declarações dos intelectuais orgânicos da oligarquia para descobrir justificativas e prever racionalizações. Sua ideologia prática (que posava de "teoria política liberal") era, mesmo no fim da IV República, uma dublagem para a mesma língua das formulações ultraconservadoras do triunvirato autoritário brasileiro (Francisco Campos, Oliveira Vianna e Azevedo Amaral). Conforme a lição do jornalista de 0 Estado de S. Paulo, "democracia [...] não é de forma alguma um regime político que uma comunhão humana qualquer possa adotar quando melhor the pareça. Democracia é essencialmente uma determinada fase da evolução social não de todos, mas de certos povos apenas". Assim como na doutrina de Francisco Campos, o Brasil não estava entre eles (nem mesmo São Paulo), e a maior falta daqueles que escreveram a Constituição de 1891, privados do conhecimento do "meio brasileiro", sempre dispostos "a buscar na literatura universal princípios" políticos abstratos, era não atentar para o fato de que aquela forma de governo 
não "correspondia ao estado amorfo e indiferenciado que então caracterizava a nacionalidade". O propósito heróico do ex-Ministro da Justiça (remover as "montanhas de intoxicação" ideológicas interpostas entre as "massas" e a verdadeira teoria democrática) desdobra-se, por sua vez, em um arrazoado que era uma cópia fiel do juridicismo liberal tradicional, só que temperado com as recomendações de "política objetiva" de Oliveira Vianna. Um exemplo: se "o Congresso é inoperante" e se "em seu seio os debates se eternizam", o remédio está em providenciar "assessorias técnicas" e outros meios políticos modernos para um "melhor entrosamento com os órgãos técnicos da Administração” (MESQUITA FILHO, 1964, p. 10-11, 19; RAO, 1964, p. 82, 89; grifos no original).

Essas evidências não são avulsas. A aproximação ideológica das classes dirigentes de São Paulo do Estado Novo poderia resultar também de uma inesperada e inusitada empatia. Conforme explicou Boris Fausto, "o PRP - desde os anos vinte - quando na Itália se implantou o fascismo, encontrou uma fórmula racionalizadora para sua prática política divorciada dos princípios da Constituição de 1891". O partido "passou a defender um 'regime de autoridade' e a referir-se à superação da democracia liberal. No órgão do partido (Correio Paulistano), Mussolini recebeu frequientes elogios" (FAUSTO, 1972, p. 84; sem grifos no original). O Partido Constitucionalista não ficava atrás e seu celebrado governo (1934-1937) antecipou em alguns anos o letreiro que distinguiria o Estado Novo, ao combinar, ele também, uma crítica genérica à "política" (entendida como expressão ilegítima do conflito social e lugar de interesses menores e escusos, cujo paradigma era a politicagem descarada, celebrada e praticada pelo rival PRP) com o elogio galante à "administração" (entendida como o princípio da eficiência, da racionalidade e da neutralidade, cujo exemplo acabado seria justamente a gestão apolítica de Armando de Salles Oliveira). Essa representação bastante generosa de si e onerosa do outro se projetava e se justificava graças ao progresso econômico do estado (a "locomotiva" do Brasil), fato promovido e garantido pela administração científica dos problemas do Estado. Tanto melhor para todos que essa ordem econômica garantia-se ao garantir a ordem política e social. No caso, "democracia" era, para os constitucionalistas, igual a hierarquia e discipli- 
na, e seu fundamento deixava de ser a preservação "dos direitos individuais" (o princípio liberal) e passava a ser a valorização do coletivo, do social, visto como ameaçado de desagregação" pelo comunismo (COHEN, 1997, p. 280). Tal e qual.

Acredito ser possível estimar o grau de consciência, solidariedade e coesão da elite paulista baseando-se na visão de mundo alegada por sua vanguarda pró-getulista e, em especial, por sua proximidade ou distância da ideologia de Estado.

\section{Conclusões}

Talvez fosse útil sintetizar meu "modelo" para expor e explicar as normas de interação entre elites, idéias e instituições no universo político e, principalmente, as propriedades dessas relações a partir do mundo político brasileiro.

Conforme postulei, há duas variáveis, ou variáveis de dois tipos, para localizar os agentes políticos no espaço social, entender suas predisposições mentais e a maneira como elas idealmente se formam, o que permitiria "prever" a ação desses agentes políticos em particular: i) uma variável estrutural (estabelecida com base em um raciocínio indutivo) e ii) uma variável histórica (estabelecida, por sua vez, com base em um raciocínio dedutivo).

A variável estrutural ("estrutural”, aqui, significa padrões permanentes que dirigem ou influenciam condutas) está subsidiada por processos de dois tipos: subjetivamente, pelo conformismo lógico, pensado não no registro original (contribuindo para a "coesão social”), mas, de maneira mais restrita, como responsável pelo esprit de corps e, no caso desse pequeno e distinto grupo, pelo effet de corps (Bourdieu), qualidade que tende a assegurar a unidade política e contribuir para a "integração moral" (Giddens) da elite; objetivamente, pelo compromisso pragmático que todos os agentes políticos firmam com a estrutura política quando aceitam participar do jogo político: logo, o instinto de preservação do Homo politicus racional na verdade recobre e disfarça o instinto de preservação da estrutura política como tal.

Já a variável histórica é formada, aqui, por três elementos, que, combinados, incidem sobre a subjetividade desses agentes, 
sendo também responsável pela mudança de sensibilidade política dos políticos de São Paulo e por sua conversão definitiva ao autoritarismo. Esses elementos são: i) a ideologia de Estado, a fórmula política e suas respectivas influências sobre a "produção estatal dos espíritos”; ii) o tipo específico de profissionalização política que confirma e reforça essa fórmula política, aprofundando o effet de corps e iii) a predisposição autoritária da elite.

Mais do que opções metodológicas, opções de enfoque implicam, necessariamente, perdas e ganhos para a análise. Julguei adequado explicitar os conceitos e as noções que orientaram a formulação daquela hipótese para enfatizar conexões causais (ou os "mecanismos" em operação, uma pretensão menos ambiciosa ${ }^{13}$ ) e sublinhar o problema mais comum em estudos históricos, que é a tentação do ensaísmo. Usualmente, segundo a lembrança do crítico André Borges (2007, p. 8), essas abordagens "igualam estudos de caso a 'story-telling'". No estudo de processos, a narrativa - $o$ que aconteceu? - é fundamental, mas é preciso tentar converter a reconstituição de como as coisas se deram em explicações. Andrew Bennett e Alexander L. George assinalaram que esse continua sendo o estilo (e a pretensão) da Ciência Política (cf. Bennett \& George apud ELMAN \& ELMAN, 2001, p. 148).

\section{Referências bibliográficas}

AMARAL, S. M. O teatro do poder: as elites políticas no Rio Grande do Sul na vigência do Estado Novo. Porto Alegre. Tese (Doutorado em História). Pontifícia Universidade Católica do Rio Grande do Sul, 2006.

ANDRADE, A. O estado nacional e a missão de Cultura Política. Cultura Política, Rio de Janeiro, v. 2, n. 18, p. 9, 1942.

. Almir de Andrade. Depoimento concedido em 1981. Rio de Janeiro: Fundação Getulio Vargas, 1985.

13 Ver Mahoney (2001), que consiste em uma resenha de Hedström e Swedberg (1998) e de Ragin (2000). 
BENNETT, A. \& GEORGE, A. L. Case Studies and Process Tracing in History and Political Science: Similar Strokes for Different Foci. In: ELMAN, C. \& ELMAN, M. F. (eds.). Bridges and Boundaries. Historians, Political Scientists, and the Study of International Relations. Cambridge, Mass.: MIT, 2001.

Bibliografia sobre o Estado Novo. Cultura Política, Rio de Janeiro, v. 1, n. 9, p. 172-178, 1941.

BLACK, G. S. A Theory of Professionalization in Politics. American Political Science Review, Washington, D. C., v. 64, n. 3, p. 865, Sept.1970.

BLOCK, F. Beyond Relative Autonomy: State Managers as Historical Subjects. In: . Revising State Theory: Essays in Politics and Postindustrialism. Philadelphia: Temple University, 1987.

BOITO JR., A. O sindicalismo de Estado no Brasil: uma análise crítica da estrutura sindical. Campinas: UNICAMP; São Paulo: Hucitec, 1991.

BORGES, A. Desenvolvendo argumentos teóricos a partir de estudos de caso: o debate recente em torno da pesquisa históricocomparativa. Trabalho apresentado no XXIV Simpósio Nacional de História da Associação Nacional de História (ANPUH), realizado em São Leopoldo (Rio Grande do Sul), de 15 a 20 de julho.2007.

BOURDIEU, P. Effet de champ et effet de corps. Actes de la Recherche en Sciences Sociales, Paris, v. 59, n. 1, p. 73, 1985.

Paris: Minuit, 1989.

. La noblesse d'État: grandes écoles et esprit de corps. . Espíritos de Estado: gênese e estrutura do campo burocrático. In: ação. Campinas: Papirus, 1996.

. O interesse do sociólogo. In: . Coisas ditas. São Paulo: Brasiliense, 2004. Razões práticas: sobre a teoria da CARONE, E. O Estado Novo (1937-1945). São Paulo: Difel, 1976.

CODATO, A. O Departamento Administrativo do Estado de São Paulo na engenharia institucional do Estado Novo. Revista de Sociologia e Política, Curitiba, n. 9, p. 115-127, 1997. 
CODATO, A. \& GUANDALINI JUNIOR, W. Os autores e suas idéias: um estudo sobre a elite intelectual e o discurso político do Estado Novo. Estudos Históricos, Rio de Janeiro, v. 32, p. 145-164, 2003.

COHEN, I. S. Para onde vamos? Alternativas políticas no Brasil (1930-1937). São Paulo. Tese (Doutorado em História Social). Universidade de São Paulo, 1997.

COSTA, C. Contribuição à história das idéias no Brasil. Rio de Janeiro: Civilização Brasileira, 1967.

DAGNINO, E. State and Ideology: Nationalism in Brazil, 1930-1945. Stanford. Tese (Doutorado em Ciência Política). Stanford University, 1985.

EAGLETON, T. Ideologia: uma introdução. São Paulo: UNESP, 1997.

ECKSTEIN, H. Case Study and Theory in Political Science. In: GREENSTEIN, F. I. \& POLSBY, N. (eds.). Handbook of Political Science. V. 7: Strategies of Inquiry. Readding: Addison-Wesley, 1975.

FAORO, R. A ponte suspensa. In: político brasileiro? São Paulo: Ática, 1994. . Existe um pensamento

FAUSTO, B. Pequenos ensaios da história da República (1889-1945). Cadernos Cebrap, São Paulo, n. 10, p. 84, 1972.

GIDDENS, A. Elites in the British Class Structure. In: STANWORTH, P. \& GIDDENS, A. (eds.). Elites and Power in British Society. Cambridge: Cambridge University, 1974.

GRAMSCI, A. Cadernos do cárcere. Vol. 5: O Risorgimento. Notas sobre a história da Itália. Rio de Janeiro: Civilização Brasileira, 2002.

HEDSTRÖM, P. \& SWEDBERG. R. (eds.). Social Mechanisms: An Analytical Approach to Social Theory. Cambridge: Cambridge University, 1998.

KAPLAN, A. \& LASSWELL, H. Poder e sociedade. Brasília: UNB, 1998.

KING, G.; KEOHANE, R. O. \& VERBA, S. Designing Social Inquiry: Scientific Inference in Qualitative Research. Princeton: Princeton University, 1994.

LAMOUNIER, B. A Ciência Política no Brasil: roteiro para um balanço crítico. In: (org.). A Ciência Política nos anos 80. Brasília: UNB, 1982. 
. Formação de um pensamento político autoritário na Primeira República: uma interpretação. In: FAUSTO, B. (org.). História geral da civilização brasileira. Tomo III: "O Brasil Republicano”, v. 2: “Sociedade e Instituições (1889-1930)”. Rio de Janeiro: B. Brasil, 1991.

LUKES, S. O poder. Brasília: UNB, 1980.

MAHONEY, J. Beyond Correlational Analysis: Recent Innovations in Theory and Method. Sociological Forum, v. 16, n. 3, p. 575-593, Sep.2001.

MARCONDES FILHO, A. O sentido de São Paulo no destino do Brasil. In:_ Vocações da unidade: conferências e discursos. Rio de Janeiro: José Olympio, 1941.

MARQUES, T. H. R. \& OLIVEIRA, O. A. São Paulo contra a dictadura: da invasão revolucionária de 30 à queda do governo Waldomiro e nomeação do Dr. Armando Salles para a Interventoria paulista. São Paulo: Elo, 1934.

MESQUITA FILHO, J. A democracia e o fenômeno brasileiro. In: Fórum Roberto Simonsen. A doutrina democrática e a realidade nacional. São Paulo: Federação e Centro das Indústrias do Estado de São Paulo, 1964.

MOSCA, G. The Ruling Class (Elementi di Scienza Politica). New York: McGraw-Hill, 1939.

QUARTIM DE MORAES, J. Ideólogos autoritários e teorias sobre o autoritarismo: uma síntese crítica. Filosofia e Política, v. 3, p. 195-216, 1986.

RAGIN, C. C. Fuzzy-Set Social Science. Chicago: Chicago University, 2000.

RAO, V. Fundamentos jurídicos dos ideais democráticos. In: Fórum Roberto Simonsen. A doutrina democrática e a realidade nacional. São Paulo: Federação e Centro das Indústrias do Estado de São Paulo, 1964.

RUESCHEMEYER, D. Can One or a Few Cases Yield Theoretical Gains? In: MAHONEY, J. \& RUESCHEMEYER, D. (eds.). Comparative Historical Analysis in the Social Sciences. Cambridge: Cambridge University, 2003. 
SILVA, R. A ideologia do Estado autoritário no Brasil. Chapecó: Argos, 2004.

THOMPSON, E. P. A peculiaridade dos ingleses e outros artigos. In: LUIGI, A. \& SILVA, S. (orgs.). Coleção Textos Didáticos, Campinas, v. 1, n. 10, jan.1998.

VARGAS, G. O aparelhamento e a renovação do Exército. In:

A nova política do Brasil. V. VII: No limiar de uma nova era. $\overline{\text { Rio de }}$ Janeiro: J. Olympio, 1940.

VIANNA, O. Problemas de política objetiva. São Paulo: Nacional, 1930.

WILLIAMS, R. Cultura. Rio de Janeiro: Paz e Terra, 1992.

WRIGHT MILLS, C. A elite do poder. Rio de Janeiro: J. Zahar, 1981. 